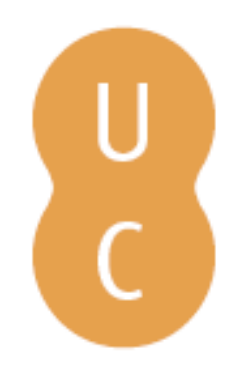

\title{
pompalina
}

Dinâmica das relações entre espaço, turismo e religiosidade em Coimbra

Autor(es): $\quad$ Bastos, Ana Paula Pinto

Publicado por: Imprensa da Universidade de Coimbra

URL

persistente: URI:http://hdl.handle.net/10316.2/43534

DOI: $\quad$ DOI:https://doi.org/10.14195/978-989-26-1343-7_37

Accessed : $\quad$ 26-Apr-2023 12:04:55

A navegação consulta e descarregamento dos títulos inseridos nas Bibliotecas Digitais UC Digitalis, UC Pombalina e UC Impactum, pressupõem a aceitação plena e sem reservas dos Termos e Condições de Uso destas Bibliotecas Digitais, disponíveis em https://digitalis.uc.pt/pt-pt/termos.

Conforme exposto nos referidos Termos e Condições de Uso, o descarregamento de títulos de acesso restrito requer uma licença válida de autorização devendo o utilizador aceder ao(s) documento(s) a partir de um endereço de IP da instituição detentora da supramencionada licença.

Ao utilizador é apenas permitido o descarregamento para uso pessoal, pelo que o emprego do(s) título(s) descarregado(s) para outro fim, designadamente comercial, carece de autorização do respetivo autor ou editor da obra.

Na medida em que todas as obras da UC Digitalis se encontram protegidas pelo Código do Direito de Autor e Direitos Conexos e demais legislação aplicável, toda a cópia, parcial ou total, deste documento, nos casos em que é legalmente admitida, deverá conter ou fazer-se acompanhar por este aviso.

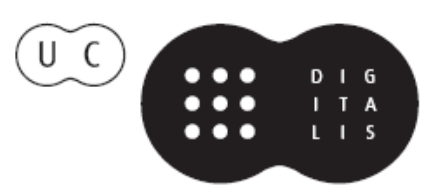




\section{FERNANDA CRAVIDÃO}

\section{IÚCIO CUNHA}

PAULA SANTANA

\section{NORBERTOSANTOS}

(ORG.)

\section{ESPAÇOS E TEMPOS EM GEOGRAFIA}

HOMENAGEM A ANTÓNIO GAMA

IMPRENISA DÁ UNIVERSIDADE DE COIMBRA COIMBRA UNIVERSITY PRESS

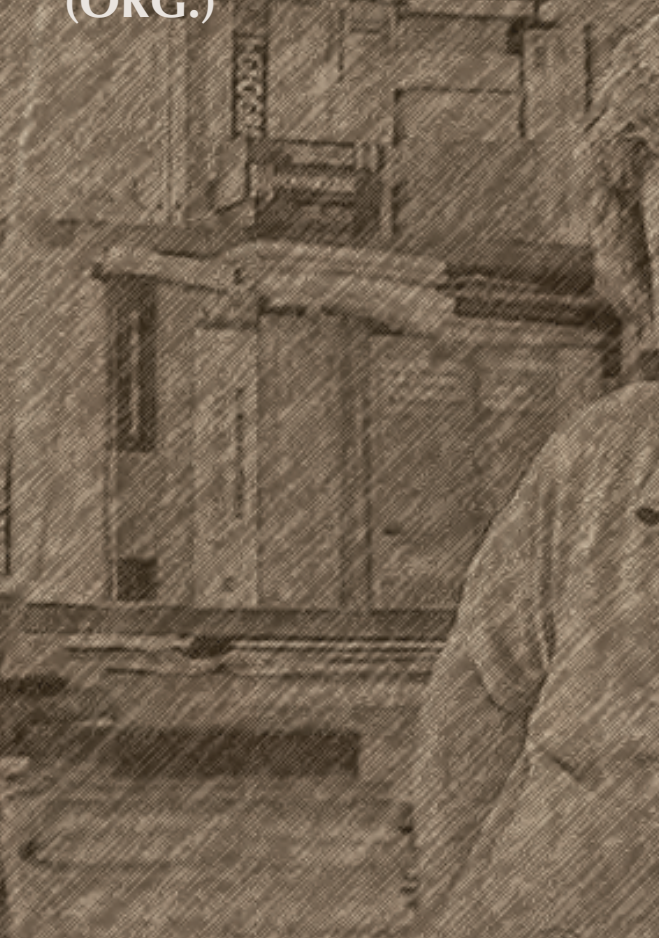




\section{DINÂMICA DAS RELAÇÓES ENTRE ESPAÇO, TURISMO E RELIGIOSIDADE EM COIMBRA}

\section{Ana Paula Pinto Bastos/paulaappb@gmail.com}

\section{Introdução}

O texto aborda questôes da relação entre turismo e religião em Coimbra e dá especial atenção a três personalidades históricas que tiveram parte da sua vivência em Coimbra: Santo António dos Olivais, a Rainha Santa Isabel e a Irmã Lúcia.

Foram contemplados conceitos significativos para o desenvolvimento do trabalho, através das contribuiçóes de Zeny Rosendahl (2012), Fátima Castro (2011), Norberto Santos (2012), Henri Lefebvre, (1973), Rogério Haesbaert (2004), Marcos Saquet (2013), Anthony Giidens (1989), Torsten Hägerstrand (1978), David Harvey (1992), entre outros. Não entraremos nas discussóes do espaço social, pois envolveria conteúdos vastos, epistemológicos e antropológicos, como Bourdieu aponta como base numa posição "construtivista estruturalista, em abordagens do espaço social, no entanto o autor aponta espaço físico e espaço social como categorias distintas (Bourdieu, 1997: 60).

Foram apresentados alguns aspetos dos itens contemplados na pesquisa. A escolha da temática justifica-se pela importância de Coimbra no contexto histórico e religioso em relação ao país, pois foi a primeira capital do reino, numa época que Lisboa (capital atual) ainda estava ocupada pelos Mouros (árabes/ mulçumanos). Outra razão refere-se ao desafio de compreender a ocupação dos 
referidos espaços escolhidos, para o estudo como lugares de beleza e significância religiosa, além de envolverem histórias de humanidade e solidariedade.

\section{Aspetos espaciais, históricos e religiosos}

A produção do espaço na região urbanizada de Coimbra conforme Santana (1996), pode ser explicada pelo sistema de transportes e a própria evolução destes. Novos espaços surgem com suas especificidades nos quais apareceram os prédios residenciais nas novas zonas da cidade. Este crescimento foi acompanhado pela construção das novas vias de comunicação e infraestrutura do núcleo primitivo da cidade que está atualmente ocupado sobretudo por comércio e serviços, havendo assim, uma desconfiguração do espaço residencial. Com a construção de novos Espaços Universitários (Polo II na Quinta da Boa Vista e Polo III em Celas), ocorre um crescimento que impulsiona um movimento de expansão urbana. Essa dinâmica espacial contribui para o surgimento de novas centralidades como: Celas, Solum e Vale das Flores. A cidade possui um patrimônio de valor arquitetónico, com grande potencial cultural e turístico que traz à tona um significado histórico e importante para Portugal.

O espaço de religiosidade de Santo Antônio dos Olivais está localizado no cimo de uma colina na cidade de Coimbra, geograficamente na Freguesia de Santo António dos Olivais, na Igreja do antigo Convento de Santo Antônio que foi destruído por um incêndio no início do século xix. Ali existia uma capela dedicada a Santo Antão, que recebeu em 1217-1218 os primeiros franciscanos chegados a Portugal, que posteriormente ergueram ao lado um "eremitério" que chegou a ser ocupado pelos Santos Mártires de Marrocos que, segundo a Igreja Católica, foram os primeiros franciscanos a serem sacrificados pela fé de Cristo. Com a vinda para o Mosteiro de Santa Cruz de Coimbra das relíquias (prováveis restos mortais), Santo Antônio deixou o Mosteiro Crúzio para se tornar franciscano, mudando o seu nome de Fernando para Antônio e, seguindo os mesmos passos dos mártires, indo para Marrocos. Com sua canonização, em 1233, é mudada a invocação deste templo e os franciscanos transferem-se 
para o Convento de São Francisco em Santa Clara. Porém, a Igreja dos Olivais representa um espaço que traz para a cidade de Coimbra um sistema religioso, de fé católica que envolve seus adeptos em nível local e no campo simbólico. $\mathrm{Na}$ análise de Rosendahl (2002), a ideia de que existe mais simbolismo nos objetos e nas coisas do que a aparência indica reconhecer o valor mercantil como valor cultural de um bem simbólico.

No contexto regional, o Mosteiro de Santa Clara-a-Nova que abriga o solar da Rainha Santa Isabel, sendo seu túmulo, é uma obra de grande valor artístico, dos mais importantes de Coimbra, denominado de túmulo-relicário que recebeu em 1677, as relíquias da Rainha Santa Isabel. Segundo informaçôes do Boletim impresso pela Confraria (2015), o sarcófago foi patrocinado pelo Bispo de Coimbra, Dom Afonso Castelo Branco com nítida influência maneirista foi criado e executado pelos ourives Domingos e Miguel Vieira, de Lisboa. Conforme registros em publicaçóes da Confraria da Rainha Santa Isabel, descendente da Casa Real de Aragão, Santa Isabel nasceu, provavelmente, em 11 de fevereiro de 1270, em Saragoça. Casou-se 11 anos depois ainda criança, por procuração, com Dom Dinis. Tornada Rainha, Dona Isabel chega a Coimbra em outubro de 1282, cidade onde se recolheu após ficar viúva e onde realizou muitas açôes de bondade acompanhadas de milagres que viriam a ter como expressão máxima a lenda da transformação do pão em rosas. A Rainha faleceu no dia 4 de julho, ano de 1336, aos 66 anos, em Estremoz e foi sepultada em Coimbra no dia 11 de Julho. O culto em torno da Rainha Santa Isabel, foi impulsionado pelas estruturas eclesiásticas e apoiado por uma forte devoção popular que seria legitimada pela sua beatificação em 15 de Abril de 1516 e canonizada em 25 de Maio de $1625^{1}$.

Pensar a dimensão econômica da religião ao visitar o Mosteiro da Rainha Santa Isabel, é inevitável, pois estão calcados aí bens simbólicos, riquezas, mercados e redes. Como diria Rosendahl (2012, p.188), nessa relação deseja-se reconhecer a dimensão geográfica do processo produtivo de bens simbólicos

${ }^{1}$ A Confraria da Rainha Santa Isabel, localiza-se em Santa Clara na cidade de Coimbra, foi fundada na data aproximada de 1562. 
ligados ao sagrado, na qual a autora questiona: como os valores são produzidos? Quem são os produtores desses bens simbólicos? Onde ocorre o processo de produçáo simbólica? Para quem desenvolve o culto cristão voltado ao catolicismo, as respostas ou explicaçôes seriam mais simples: "fé", "um milagre" ou "os milagres", "poder de Deus", numa percepção ou natureza de seu significado que está inserido na difusão da fé e identidade religiosa. O respeito aos lugares sagrados por parte do cristão católico não caracteriza apenas um prédio estático, um símbolo, mas experiências às vezes vividas por entes queridos e familiares, simplesmente experiências humanas.

Em âmbito internacional, está o terceiro ícone, Maria Lúcia do Coração Imaculado, a Irmá Lúcia do Carmelo, ou a Lúcia, menina de 12 anos dos três pastorinhos de Fátima. O Carmelo de Santa Tereza está localizado à Rua de Santa Tereza, no 16 em Coimbra/ Portugal. Segundo informaçôes de Boletim impresso (No 20, Ano 7, Jan-Abr 2015), Lúcia Rosa dos Santos, nasceu em Aljustrel, paróquia de Fátima, no dia 28 de Março de 1907. Na companhia de seus primos Francisco e Jacinta Marto recebeu por três vezes a visita de um anjo (1916) e por seis vezes, a visita de Nossa Senhora (1917), que lhes pediu oraçáo e penitência em reparaçáo e pela conversão dos pecadores. Sua missáo especial consistiu em divulgar a devoção ao Coração Imaculado de Maria como alma da mensagem de Fátima. Ingressou na Congregaçáo de Santa Doroteia, em Espanha, onde se deram as aparições de Tuy e Pontevedra, as apariçóes da Santíssima Trindade, de Nossa Senhora e do Menino Jesus. Irmã Lúcia teve uma vida de recolhimento para responder e atender à mensagem que Nossa Senhora lhe tinha confiado. Entrou no Carmelo de Coimbra em 1948, onde se entregou mais profundamente à oração e ao sacrifício. Faleceu no dia 13 de Fevereiro de 2005 e o seu corpo repousa na Basílica de Nossa Senhora do Rosário, em Fátima, desde o dia 19 de Fevereiro de 2006. Irmã Lúcia viveu 57 anos na Ordem Carmelita, a Ordem de Nossa Senhora do Carmo. Sua importância para o mundo religioso e católico tem significado sagrado. Diversas publicaçôes foram editadas entre elas "Memórias da Irmã Lúcia I e II", "Apelos da Mensagem de Fátima” entre outros. Sua biografia está em Português, Inglês e Polaco. Sua beatificação está em processo sob os cuidados de Irmã Ângela 
Coelho que foi nomeada vice-postuladora da Causa da Beatificação da Irmã Lúcia, hoje conhecida no mundo católico como "serva de Deus". No endereço www.lucia.pt podemos encontrar o trecho da oração para pedir a Beatificação: "Santíssima Trindade, Pai, Filho e Espírito Santo, adoro-Vos profundamente e Vos agradeço as aparições da Santíssima Virgem em Fátima para manifestar ao mundo as riquezas do seu Coração Imaculado. Pelos Méritos infinitos do Santíssimo Coração de Jesus e do Coração Imaculado de Maria, peço-Vos que, se for Vossa maior glória e bem das nossas almas, Vos digneis glorificar, diante da Santa Igreja, a Irmã Lúcia, pastorinha de Fátima, concedendo-nos, por sua intercessão, a graça que Vos pedimos amém”.

A geografia da Religião, nos traz possibilidades de análise do espaço e da cultura, como diria Rosendhal (2012, p 220), espaço e cultura estão reunidos em novos planos de perceção teórica que não invalidam os anteriores, pelo contrário, introduzem mais uma possibilidade de pensar o sagrado e o profano na ciência geográfica. A análise nos reporta a uma convergência, um elo entre religião, oração e resiliência geográfica, talvez, que nos permite e nos fornece elementos para o reconhecimento de que existe um aspeto cultural dominante em um determinado espaço. Como reforço dos acontecimentos e fatos religiosos e sagrados, faz-se necessário aqui registrar um dos trechos da suposta visita da Virgem Maria à menina Lúcia, então naquela época com 12 anos, em Valinhos na Cova da Iria na data, 13 de Junho de 1917, em Fátima: “Tu ficas cá, mais algum tempo. Jesus quer servir-se de ti para Me fazer conhecer e amar" (Boletim da Serva de Deus, N. ${ }^{\circ}$ 20, Ano 7, Jan-Abr 2015).

\section{Fundamentação teórica}

Quando a cidade envolve espaços de religiosidade, numa relação de aprofundamento das potencialidades da cultura, da história e religião, surge o aspeto turístico que se configura de maneira a valorizar as territorialidades. E aí surge um diálogo intercultural que nas palavras de André (2012: 501): (...) nas suas dimensóes e acentuando a consciência da sua incontornável natureza que radica 
na sua forma peculiar de configuração de mundividências e comportamentos e na fonte de sentido que confere à existência cotidiana, na relaçáo dos homens entre si, dos homens com o mundo e dos homens com o mistério que os ultrapassou com o sagrado que silenciosamente os inspira num convite à contemplação e ao enraizamento no fundo indivisível de uma transcendência acolhida na interioridade do humanum. (André, 2012: 501).

A dinâmica espacial à qual nos referimos envolve espaços de visitação turística e religiosa em Coimbra, cidade de grande riqueza arquitetônica e histórica em Portugal. A área a ser estudada envolve espaços históricos inseridos no espaço territorial, entre eles: Santo Antônio dos Olivais, São Martinho do Bispo e Uniáo de freguesias de Coimbra. O que nos induz a uma pequena análise sobre Território. É inevitável não falarmos de termo. "A história do homem sobre a Terra é a história de uma rotura progressiva entre o homem e o entorno", já dizia Mílton Santos (1997). É notoriamente perceptível a relação intrínseca entre "Território" e "Sociedade", pois segundo o autor citado, em 1992, afirmava que o problema do espaço ganhava uma dimensáo que ele náo havia obtido jamais antes, sabendo nós que a análise territorial está sempre imbuída do elemento social e a problemática da base territorial da vida humana sempre preocupou a sociedade.

Sobre Território, a partir de 1970, diversas abordagens foram realizadas para explicar o significado, através das obras de G. Deleuze, A. Gramsci, G. Dematteis, M. Foucault entre outros. Porém tais reflexôes se juntaram às de Henri Lefebvre, sobretudo nos anos 1970, 1973 e 1976. As redes de comunicação e cotidianeidade, foram evidenciados por Lefèbvre (1973), significativas para a "redescoberta" do Território. Entretanto, consideramos significativo nos reportar à contribuiçấo de Saquet (2013), na qual afirma que entender o território, apenas como produto de centralidade e autoridades, realmente é uma forma reducionista e evidencia que o que é meu não é teu e o que é teu não é meu, mas considera muito pouco diante da complexidade da construção do território. Para o autor, o território significa natureza e sociedade; economia, política e cultura, ideia e matéria, identidades e representaçôes, apropriação, dominação e controle, descontinuidades, conexão e redes, domí- 
nio e subordinaçãa, degradaçấo e proteção ambiental, terra, formas espaciais e relaçôes de poder.

Segundo Lefèbvre, in Saquet (2013), é na década de 1960 que se passa uma compreensão da produçáa direta do espaço, em vez da descrição e quantificação da produçáo indireta no espaço, o que é praticamente, concomitante. É primordial a discussão abordada por autores italianos com Dematteis (1970) e Quaini (1974) que destacam a importância da utilização de princípios do materialismo histórico e dialético. Pois para Quaini (1974), uma das grandes questôes na renovação da geografia é envolvida pelas relações natureza-história na organizaçâo territorial do capitalismo. É preciso que se diga, que é evidente a relação dialética entre natureza, sociedade e território, visto que ocorrem aí os processos das relaçôes de produção e relaçóes sociais.

A forma como o homem utiliza o espaço, ou os espaços, pode variar de cidade para cidade ou de um tempo para outros tempos. No que se refere especificamente ao conceito de espaço, à partir da Geografia como Ciência Moderna, diversos geógrafos estudiosos discutem o tema onde apresentam divergências conceituais. Mílton Santos fala de "destemporalização" e afirma: "Destemporalizando o espaço e desumanizando-o, a geografia acabou dando as costas ao seu objeto e terminou sendo uma 'viúva do espaço' (Santos, 2002, p. 119).

Sorre (1967), entende a Geografia Humana como "descrição do ecúmeno" ou "descrição científica das paisagens humanas e sua distribuição pelo Globo". É a disciplina dos "espaços terrestres". Significa estudar os grupos humanos vivos, sua organização espacial, seu movimento, suas técnicas (técnica entendida como "alto grau de desenvolvimento mental"), a relaçáo do homem com o meio (uma ecologia do homem com enfoque espacial) e a formaçáo dos gêneros de vida. O método consistiria em descrever a paisagem, incorporando também uma ferramenta importante que é a imaginação. É necessário recorrer às outras ciências no que for necessário. O espaço é visto como localização (através dos mapas) e extensão. Sorre, chega ao ponto de afirmar, como H. Baulig, que a Geografia é um mero ponto de vista. Moreira (1997) entende o espaço geográfico como estrutura de relaçôes sob determinação do social; é a sociedade vista com sua expressão material visível, através da socialização da natureza pelo trabalho. 
"A Geografia estuda também "a dinâmica do espaço humanizado" através da técnica, da intencionalidade (possibilidades da açâo humana) e das relaçôes entre as forças naturais e as forças "históricas" (George, 1973).

No que se refere ao conceito de Turismo, Castro (2011) refere: o impulso do indivíduo para viajar é mais do que uma capacidade, uma necessidade intrínseca que o acompanha desde sempre e a Geografia, como ciência, aborda o território em íntima associação com a mobilidade, privilegia por uma questáo pragmática e por uma valência cientificamente afetiva, o olhar sobre a viagem no seu movimento dual de "sentido".

A Organização Mundial do Turismo/Naçóes Unidas concebe o Turismo como: "as atividades que as pessoas realizam durante suas viagens e permanência em lugares distintos dos que vivem, por um período de tempo inferior a um ano consecutivo, com fins de lazer, negócios e outros." Não há uma definição única de turismo! Diversos autores comentam, analisam e discutem essa atividade, a qual se amplia à medida que as fronteiras entre países e ligaçôes intercontinentais vão aumentando, tanto do ponto de vista econômico como geográfico. Assim sendo, podemos dizer que Turismo é um movimento econômico e cultural que envolve pessoas dispostas a passear, comprar, testar comidas e atividades de lazer diferentes, circular e observar, numa interaçấo social envolvente. As tipologias são variadas, entre as quais está claramente o Turismo Religioso, que se entrecruza amiúde com a peregrinação.

É importante salientar que o crescimento da atividade turística na Europa vem ocorrendo e nem as crises mundiais (crises do Petróleo em 1973 e 1979, crise da bolha dos Dot.com em 2000 e por último a crise imobiliária e financeira em 2008) conseguiram travar o crescimento contínuo, considerando assim, o setor de atividade mais resiliente do mundo.

No caso de Portugal, existem Departamentos orientados para o Turismo Religioso e Cultural como por exemplo, o GeoStar localizado em Lisboa e no Porto que realiza viagens turísticas chamadas de "Viagens Personalizadas", que oferecem um serviço ao turista com passagens, hotel e passeios ${ }^{2}$. Em países

\footnotetext{
${ }^{2}$ GeoStar http://turismoreligioso.geostar.pt/home/s-4.
} 
da América Latina como o Brasil, conforme Embratur-Empresa Brasileira de Turismo, em 2014, o Santuário de Aparecida do Norte, no Estado de São Paulo (regiáo Sudeste do Brasil), recebeu mais de 12 milhôes de visitantes, número que corresponde a quase o dobro de pessoas que visitaram em 2013 a Torre Eiffel, em Paris, segundo dados de pesquisa da Euromonitor Internacional, na WTM Latino América, que aconteceu no final de Abril em São Paulo. Ainda no ano passado (2014), 7,7 milhōes de viagens domésticas foram motivadas pela fé, segundo estimativas do Ministério do Turismo. O fato do Brasil ser o país com maior número de católicos do mundo, com cerca de $12 \%$ da população católica mundial, conforme dados do Vaticano explica a importância religiosa no país.

O Turismo Religioso vem se desenvolvendo há algum tempo em vários países. Algumas cidades possuem potencial e visibilidade, bem como uma dimensão econômica como a cidade de Fátima em Portugal, a Mesquita de Jerusalém/Israel com a cúpula de pedra perto do Templo de Salomão (maior monumento do Islã), Aparecida do Norte em São Paulo/Brasil (os devotos de Nossa Senhora Aparecida) e Juazeiro do Norte/Ce/Brasil com a fé dos cristãos, seguidores de Padre Cícero, (popularmente conhecido como "Padim Pade Cíço").

A atividade turística requer visitação no lugar como espaço de contemplação, valorizaçáo de algo como objeto de um olhar específico, um olhar de cada ser humano. Podemos dizer que a visitação envolve um destino ou vários destinos ao mesmo tempo, onde possam estar reunidos em lugares próximos uns dos outros e com deslocamentos longos ou curtos. Porém, a perspetiva contemplativa com uso do espaço para visitação, do ponto de vista turístico, religioso, histórico ou cultural deve convergir sempre para a sustentabilidade urbana e integração de espaços. No entanto, em publicação na Revista Brasileira Mercator, disse Santos (2011): “A cidade é responsável pela organização espacial de uma sociedade crescentemente dependente do poder de um mercado neoliberal que dá valor a perceçóes globais, mas que depende das actuaçôes locais de agentes que precisam de estar bem preparados e apoiados em estruturas de relação bem sustentadas". 
A apresentaçấo da cidade para quem passa, para quem vê, observa ou aprecia, pode trazer "olhares" diversos, perspectivas diversas, interpretaçóes multiculturalizadas com significados comuns que podem náo incluir uma "sustentabilidade urbana". Sobre religiosidade é inevitável a relação entre "Religião" e "Espiritualidade"... O que caracteriza a religiosidade é, assim, a atitude particular de uma consciência transformada pela experiência do numinoso (Jung, 1938/1990, p. 10).

A palavra sociedade vem do latim societas, que significa "associação amistosa com outros". Podemos dizer que é um conjunto de seres que convivem de forma organizada. Para Émile Durkheim (2007), o homem é coagido a seguir determinadas regras em cada sociedade, o qual chamou de fatos sociais, que são regras exteriores e anteriores ao indivíduo e que controlam sua ação perante os outros membros da sociedade. Assim sendo, ela controla as açôes individuais, o indivíduo aprende a seguir normas que náo foram criadas por ele. Mesmo o indivíduo possuindo sua autonomia, seu livre arbítrio, as escolas estáo dentro dos limites que a sociedade impóe, de maneira que se o indivíduo ultrapassar os limites, as regras impostas, será punido socialmente. Na visão de Karl Marx (1984), a sociedade é heterogênea e constituída por classes sociais que se mantêm, por meio de ideologias dos que possuem o controlo dos meios de produçáo que pertencem às elites. Dessa forma, em uma sociedade capitalista, o acúmulo de bens materiais é valorizado, enquanto o bem-estar coletivo fica em segundo plano. $\mathrm{O}$ autor analisa dizendo que falta ao trabalhador a consciência de classe para superar a ideologia dominante do capitalismo e assim finalmente realizar a revolução para se chegar ao socialismo. Weber realiza estudos das situaçóes sociais concretas quanto às suas singularidades, nos quais trabalha também o conceito de poder. Para Weber (2004), a sociedade constitui um sistema de poder que perpassa todos os níveis da sociedade, desde as relaçôes de classe a governados e governantes, como nas relaçôes cotidianas na família ou em uma empresa. O poder náo decorre somente da riqueza e do prestígio, mas também de outras fontes, como exemplo: o carisma, a tradição e o conhecimento técnico-racional. 


\section{Metodologia}

A metodologia utilizada seguiu um caráter qualitativo, o qual proporcionou aos entrevistados o livre arbítrio para expressarem suas ideias e conclusóes livremente sobre o tema, na busca de interpretaçôes e entendimento sobre uma questấo a ser interpretada. Esta pesquisa procura entender as razôes, ou motivos de um determinado comportamento ou ação, para entender as perceçôes que as pessoas têm a respeito de um assunto ou serviço, que no nosso caso se refere à visitação aos Monumentos. Foram aplicadas entrevistas semiestruturadas diretamente ao representante religioso, habitante, visitante/turista em Coimbra. A amostra por conveniência limitou-se a 9 entrevistas, realizadas em cada monumento (ícone religioso). Foram distribuídas 3 entrevistas direcionadas a um visitante, um habitante e um representante religioso de cada ícone. No entanto, a análise proposta teve o intuito de náo abarcar a totalidade dos aspetos religiosos da Cidade de Coimbra, pois a riqueza, grandeza e importância histórica têm dimensão maior.

De acordo com informações da Câmara Municipal, Coimbra teve como nome romano Aeminium, que está relacionado com a topografia local ocupado pelo povoado o meneiu, ou seja o topo do morro, época oriunda do período visigótico entre 569-589. O nome sofreu transformaçóes "Conimbriga", "Colimbria" até chegar ao nome atual. O morro com formaçóes calcárias era contornado por terras que são banhadas pelo rio Mondego. Todavia, lembramos que devido à perspectiva espacial e geográfica iremos nos limitar ao proposto, pois a história contempla fatos significativos, longos, seguindo uma trajetória recheada de fatos enriquecedores até os dias de hoje.

\section{Resultados e discussão}

A análise segue uma direção específica de discussão observando as ponderaçôes dos entrevistados e suas visóes de mundo no contexto religioso, turístico e espacial. A investigaçáo foi desenvolvida em 2015. Contou na totalidade com 
a participação de nove (09) pessoas entrevistadas, entre elas: representantes religiosos, (uma Freira, um Frei e um Agente da Confraria da Rainha Santa). No primeiro ícone contemplado para o estudo, a Igreja de Santo Antônio dos Olivais, o representante entrevistado foi Frei Domingos, italiano, que mora em Coimbra há 20 anos, e representa a paróquia da Igreja de Santo Antônio dos Olivais; a entrevistada na categoria habitante, foi uma professora de português e francês do ensino secundário; e o visitante foi uma senhora com descendência brasileira, evangélica da Igreja Batista. Sobre a origem dos visitantes todos responderam que são do estrangeiro e também da cidade. O Frei Domingos afirmou que são em torno de $70 \%$ católicos, fez uma observação mais voltada para o contexto católico, no qual externou uma informaçáo. No item 2, sobre o perfil, sáo de maneira geral católicos, ainda que o Frei tenha considerado um perfil heterogêneo, vindos de Coimbra com $12 .^{\circ}$ ano.

No item relativo ao significado do espaço religioso, as respostas foram diferentes, pois uma entrevistada é evangélica, o grau de importância difere dos outros dois. Para o habitante, é de grande valia esse espaço, na perspetiva cultural e arquitetônica. O que reflete, por parte da professora é o cuidado e o zelo com a importância histórica e religiosa para a cidade. Na relação espaço e culto com a cidade, está visível sua importância na religiáo católica, confirmando um poder mantido, produzido ou reproduzido pela comunidade.

Na perspetiva de Bonnemaison, (1981: 251, in Rosendahl, 2002: 187), "é pela existência de uma cultura que se cria um território e é pelo território que se fortalece e se exprime a relaçáo simbólica existente entre a cultura e o espaço". No tocante a pergunta de número 5 , sobre a contribuiçáo dos monumentos para a cidade, a resposta do Frei foi verdadeira no sentido da história, pois traz, nos ajuda a relacionar o passado e o presente, nos reporta ao resgate das raízes da fé, num Monumento considerado vivo e vai se reproduzindo numa dinâmica que envolve pessoas em convivência harmónica na Freguesia onde habitam. Os entrevistados da Rainha Santa Isabel foram: uma servidora da Confraria que náo quis se identificar, uma moça de (34) anos; um turista português e um habitante da localidade de Santa Clara. $\mathrm{O}$ monumento considerado sagrado por muitos, pela crença e fé nos milagres 
que a santa proporcionou aos que creem nela. Constatou-se com as respostas, que a Rainha Santa, como é chamada por quase todos, trouxe à tona impressóes de bondade, lealdade e solidariedade com os pobres, entretanto seu legado de fé também deixou um monumento que proporciona a existência de um capital religioso acumulado nas mãos de um grupo que fazem a administração do local, pois não foi possível a constatação de um único dono. Como Rosendahl (2002, p.190) analisa, o capital religioso é sem dúvida um instrumento de poder e de estratégia fortemente vinculado à política econômica do capitalismo global. Assim sendo, os valores estabelecidos pela comunidade e sociedade local ou regional podem estar ou ficar concatenados com a produção de bens simbólicos.

Os entrevistados do Ícone Irmã Lúcia foram: uma freira chama de Irmã Ana Sofia de 36 anos que afirmou ter cuidado de Irmá Lúcia em sua enfermidade dos últimos anos; um habitante do entorno, um carpinteiro de 67 anos e uma visitante turista que segue a Religião das “Testemunhas de Jeová” de 42 anos. Dos três entrevistados as respostas mais significativas e que demonstraram um grande carinho e respeito pela Irmã Lúcia foi realmente as da Irmã Sofia, que falou com carinho, realçando a bondade e fraternidade da Irmã Lúcia. Demonstrou também muito conhecimento sobre o Convento das Irmãs Carmelitas e que a Igreja hoje não funciona como paróquia, mas está aberta ao público e tem missa com celebração eucarística. De maneira geral, o que se percebe e se constata com a pesquisa, é que para alguns, a Irmã Lúcia não é tão conhecida para pessoas com outras religiôes, ou sua história não é valorizada. Para outros, tem grande significância religiosa, sobretudo para os cristãos católicos, na qual não podemos deixar de abordar aqui a relação com a cidade de Fátima que abriga as apariçóes de Nossa Senhora aos pastorinhos: Lúcia, Jacinta e Antônio, três crianças na época que pastoravam uma zona rural chamada Valinhos, mais precisamente Cova da Iria. Hoje o local tem uma coluna de mármore sobre a qual é colocada a imagem de Nossa senhora, é aí que os peregrinos fazem suas oraçóes, vindos de diversos lugares do planeta. 


\section{Conclusốes}

Com intuito de apresentar as visôes, e impressôes pessoais sobre os Monumentos pesquisados, as constataçóes que ficam, são de que em Coimbra/Portugal existem muitos católicos com crença em Santo Antônio dos Olivais devido ao Santo Antônio casamenteiro, devido também a sua ligação com os frades franciscanos e sua escolha por Portugal para realizar seus votos de pobreza e fundar a sua Ordem, bem como sua história. Podemos dizer que a dimensão mercadológica, não tomou conta do lugar e a comunidade local, que está voltada para a cultura do "Santo Antônio casamenteiro" frequenta a Igreja com intuito de oração, crença e fé, não tomou a característica do capital. Entretanto, no Mosteiro da Rainha Santa Isabel em Coimbra segue outro campo simbólico, mesmo que religioso, porém diferente.

Do nascimento de Isabel de Aragão até à santidade, muitos fatos aconteceram, como o seu casamento por exemplo com um Rei, Dom Dinis, sua trajetória de bondade, viuvez e doença que a levou à morte, aos 66 anos em 1336. Depois veio a fama de santidade e milagres aconteceram, seguidos da beatificação e grande propagação de seu culto com uma proporção nacional. Hoje o lugar é muito visitado, considerado sacro, uma Igreja, das mais prestigiadas do país, abriga um túmulo em prata que é envolvido por vidro de grande espessura e um sarcófago em ouro, reunindo ao longo de alguns séculos importante espólio artístico e também é berço de devoção dos pobres e dos nobres pela Rainha Santa Isabel. Por último o Memorial de Irmã Lúcia, que faz parte do patrimônio histórico da cidade de Coimbra, no qual recebe dos visitantes da cidade e de outros países grande respeito pelo papel que a menina Lúcia teve como "vidente", por ter vivenciado as apariçóes de Nossa Senhora na Cova da Iria em Fátima em 1917.

Outra conclusão é que a sociedade constrói identidade, território e se relaciona com o ambiente de maneira histórica e também com o mundo moderno e contemporâneo. Outra razão está a ligada ao fato de que a monumentalidade religiosa católica não se restringe aos católicos. Entretanto, é preciso que se diga que o crescimento de outras crenças também tem atraído visitantes para outros 
locais religiosos, como o caso da fé de origem africana, como o candomblé, e de cristáos evangélicos. Concluímos com essa pesquisa que a sociedade constrói identidade, território e se relaciona com o ambiente historicamente e também se relaciona com o mundo moderno e contemporâneo. Portanto, a dinâmica das relaçôes entre espaço, religião e turismo em Coimbra também envolve cultura, na qual é preciso a associação com religião numa perspetiva de entendimento no mundo contemporâneo dinâmico. A globalização se encarrega de um movimento tal, onde pode haver a união dos povos de diferentes nacionalidades, idiomas, crenças, territórios, enfim. No mundo atual de multiculturalidade e pluralidade religiosa, podemos dizer que com os rompimentos de fronteiras a busca pelo novo e o diálogo intercultural é uma constante entre os povos. Entáo, mesmo que náo haja uma convergência intercultural ou uma similar tendência religiosa, os povos se aproximam mesmo com crenças e cultos diferentes.

\section{Referências bibliográficas}

André, J. M. (2012). Potencialidades, limites e operadores do diálogo inter religioso face ao diálogo intercultural. Revista Filosófica de Coimbra, N. 42.

Ausubel, D. P. (2000). The acquisition and retention of knowledge: a cognitive view. Boston: Kluwer Academic Publishers.

Bernecker, P. (1965). Les fondements du tourisme, cours d'etudes touristiques. UIOOT, Union International des Organismes Officials du Tourisme.

Burdieu, P. (1997). Sobre a televisão. Rio de Janeiro: Jorge Zahar.

Castro, F. V. (2011). O sentido da viagem: territorialidade (s) no filme "A casa de areia", de Andrucha Waddington. Cadernos de Geografia, n. ${ }^{\circ}$ 28/29; UC pp. 73-80 - URL/PDF.

Dematteis, G. (1970). "Rivoluzione quantitativa" e nuova geografia. Laboratorio di Geografia Economica, n. ${ }^{\circ} 5$, Università degli Studi di Torino.

Durkheim, E. (2007). As regras do método sociológico. Tradução: Paulo Neves, 3. ${ }^{a}$ Edição. São Paulo: Martins Fontes.

George, P. (1973). O meio ambiente. Difusão européia do livro: saber atual. São Paulo.

Gideens, A. (1989). A constituição da sociedade. São Paulo: Martins Fontes.

Gideens, A. (1991). As consequências da modernidade. São Paulo: Ed. UNESP.

Haesbaert, R. (2004). O mito da desterritorialização. Do "fim dos territórios" à multiterritorialidade. Rio de Janeiro: Bertrand Brasil.

Hägerstrand, T. (1978). A note on the quality of the life times. In T. Carlstein, D. Parkes e N. Thrift, Time space and spacing time. London. 
Harvey, D. (1992). A experiência do espaço e do tempo. In Condição pós-moderna, São Paulo: ediçôes Loyala, pp.185-218.

Lefebvre, H. (1973). A re-produção das relaçōes de produção. Publicaçōes Escorpiōes, (Cadernos o Homem e a Sociedade).

Marx, K. (1984). Manuscritos: economia y filosofia. Traducción, introducción y notas de Francisco R. Lorente. Madrid: Alianza Editorial.

Moreira, R. (1997). Da regiáo à rede e ao lugar. Ciência Geográfica, N.o 6, Bauru, São Paulo.

Novak, J. D. (1990). Concept mapping: A useful tool for science education. Journal of Research in Science Teaching, 27 (10), 937-949.

Santana, P. (1996). Mobilidades e organização do espaço urbano de Coimbra. Cadernos de Geografia, N.o Especial, Actas do I Colóquio de Geografia de Coimbra, pp 57-66.

Santos, M. (1997). Técnica, espaço, tempo. Globalização e meio técnico informacional. São Paulo: Hucitec.

Santos, M. (2002). Por uma Geografia Nova: da crítica da Geografia a uma Geografia Crítica. São Paulo: Edusp.

Santos, N. P. (2011). Cidade e sustentabilidade territorial. Mercator, Revista de Geografia da UFC, Fortaleza, Vol. 10, n. 23, pp. 7-22.

Saquet, M. A. (2013). Abordagens e concę̧ōes de território. 3. ${ }^{a}$ Ed. São Paulo, Outras Expressōes.

Sorre, M. (1967). El hombre en la Tierra. Barcelona: Labor.

Weber, M. (2004). Economia e sociedade. Fundamentos da sociologia compreensiva. Tradução de Regis Barbosa e Karen Elsabe Barbosa, UNB, 2004. 